\title{
TRAJETÓRIAS ESPORTIVAS DE JOGADORAS DE HANDEBOL E SUAS NARRATIVAS SOBRE SER PROFISSIONAL DA MODALIDADE
}

\author{
FEMALE HANDBALL PLAYERS' SPORTS HISTORIES AND NARRATIVES \\ ABOUT BEING PROFESSIONALS
}

\author{
TRAYECTORIAS DEPORTIVAS DE JUGADORAS DE HÁNDBOL Y SUS \\ NARRATIVAS SOBRE SER PROFESIONAL DE LA MODALIDAD
}

\author{
Suélen de Souza Andres*, Silvana Vilodre Goellner*
}

Palavras chave:

Mulheres.

Handebol feminino.

Carreira esportiva.
Keywords:

Women.

Female handball.

Sports career.
Resumo: Esta pesquisa tem como objetivo analisar o processo de profissionalização de atletas praticantes de handebol de um time do Rio Grande do Sul, considerando suas trajetórias e narrativas. A fundamentação teórico-metodológica está ancorada na História Oral, e sua captação de informações está centrada na realização de quinze entrevistas com atletas da equipe adulta da APAHAND/UCS/Prefeitura de Caxias do Sul. A partir das análises, foi possível verificar a centralidade que o handebol adquire na vida dessas atletas, assim como a estreita relação construída entre sua trajetória esportiva e sua formação acadêmica. Por fim, percebemos que 0 entendimento que expressam sobre ser uma profissional da modalidade se dá mediante a relação que estabelecem com a prática do esporte e não a partir de vínculos trabalhistas que façam dessa atividade uma profissão.

Abstract: This study analyzes the professionalization process of handball athletes of a team from the Brazilian state of Rio Grande do Sul, considering their histories and narratives. Its theoretical and methodological framework is based on Oral History and information was collected during fifteen interviews with athletes from the APAHAND/UCS/ Caxias do Sul City adult team. The analysis showed handball's centrality in those athletes' life as well as the close relationship between their sports histories and their academic education. Finally, we found that their understandings about being professional handball players focus on their relationship with playing rather than the labor ties that make it a profession

Resumen: Esta investigación tiene como objetivo analizar el proceso de profesionalización de atletas de hándbol de un equipo de Rio Grande do Sul, considerando sus trayectorias y narrativas. La fundamentación teórico metodológica está anclada en la Historia Oral, cuya captación de informaciones está centrada en la realización de quince entrevistas con atletas del equipo adulto de APAHAND/UCS/Ayuntamiento de Caxias do Sul. A partir de los análisis, fue posible verificar la centralidad que el hándbol adquiere en la vida de esas atletas, así como la estrecha relación construida entre sus trayectorias deportivas y sus formaciones académicas. Por fin, percibimos que el entendimiento que expresan sobre ser una profesional de la modalidad se da mediante la relación que establecen con la práctica del deporte y no a partir de los vínculos de trabajo que hacen de esa actividad una profesión.
*Universidade Federal do Rio Grande do Sul. Porto Alegre, RS, Brasil. E-mail: suelenandres@yahoo.com.br; vilodre@gmail.com

Recebido em: 19-01-2018 Aprovado em: 08-05-2018

DOI: http://dx.doi.org/10.22456/1982-8918.79795 (c) (1) (3) Licence 


\section{INTRODUÇÃO}

O handebol de mulheres adquiriu maior visibilidade no contexto brasileiro, nos últimos anos, em função da conquista da medalha de ouro no Mundial de Handebol Feminino de 2013 e da 5a colocação nos Jogos Olímpicos do Rio de Janeiro, em 2016. Essas conquistas podem ser associadas a uma trajetória consolidada, cujos êxitos remontam à primeira participação do selecionado nacional no 1 Sul-Americano de Handebol realizado em Buenos Aires, Argentina, no ano de 1983, no qual conquistaram a terceira colocação. No decorrer de sua trajetória, a equipe conquistou medalhas em todas as treze edições do Campeonato Pan-Americano, sendo nove de ouro (1997, 1999, 2000, 2003, 2005, 2007, 2011, 2013, 2015), uma de prata (2009) e três de bronze (1986, 1989, 1991); em todas as sete edições dos Jogos Pan-Americanos, das quais cinco de ouro $(1999,2003,2007,2011,2015)$ e duas de bronze $(1987,1995)$ e, ainda, em três das quatro edições dos Jogos Sul-Americanos, sendo duas de ouro $(2002,2014)$ e uma de bronze (2010).

Apesar de ser considerada uma das grandes potências do handebol mundial, a modalidade ainda sofre, em nosso país, com uma estrutura frágil e com poucos investimentos voltados tanto para sua expansão como para a formação de atletas de base, visando dar continuidade a essa trajetória plena de significativos resultados. Esse entendimento é compartilhado por Alexandra Nascimento, considerada a melhor jogadora do mundo pela International Handball Federation, no ano de 2012. Em entrevista ao canal FoxSports Online, a atleta destaca:

No Brasil, infelizmente, handebol não é como futebol. Para ser jogadora profissional, tem que ser aqui na Europa, não tem jeito. Estou aqui faz 9 anos, jogando e treinando contra os melhores jogadores. Precisa ter esse contato. $\mathrm{Na}$ Europa, a gente treina duas vezes por dia. No Brasil, a gente não treina nem todos os dias da semana. Você não podia se entregar 100\% ao esporte, porque não dá para viver do handebol, como eu faço aqui na Europa. A situação no Brasil está melhorando agora, com a bolsa-atleta. Quando eu comecei, não tinha dinheiro para pagar passagem, comer direito, nada (SARTORATO; AZENHA, 2013).

Ao comparar o handebol com o futebol, a atleta tensiona a dificuldade de se viver do e para o esporte no Brasil. Todavia, sabemos que tal dificuldade não se restringe ao handebol, mas a várias outras modalidades esportivas, inclusive no futebol praticado por mulheres (MIRANDA, 2007; DANTAS, 2017; SOUZA JUNIOR, 2013).

Diante desse cenário, mesmo com a vitória no Campeonato Mundial e o consequente aumento da visibilidade e do reconhecimento das conquistas da seleção, ainda é incipiente a estruturação do handebol praticado por mulheres no Brasil. Em 2015, o então técnico da seleção, o dinamarquês Morten Soubak, afirmava: "Antes, diziam: 'Vocês vão ter algo depois de conquistarem um título'. Não é verdade! [...] Eu não vejo clubes, cidades ou Estados investirem no handebol" (FRANCESCHINI, 2015). Essa situação também foi evidenciada pela atleta Eduarda Amorim ao comentar: "O incentivo esperado não veio, o que não ajuda no fomento da competição, no desenvolvimento de novos atletas e na estrutura da liga em si" (COELHO, 2016).

Apesar da frequente explicitação da falta de incentivo, a seleção brasileira entrou em quadra nos Jogos Olímpicos Rio 2016 como uma das favoritas à medalha de ouro, sonho que foi interrompido nas quartas de final, ao ser derrotada pela equipe holandesa. Mesmo 
tendo conquistado a 5ª colocação na competição, o melhor resultado do handebol brasileiro entre homens e mulheres na história dos Jogos Olímpicos, a seleção nacional depara-se com outra dificuldade: a aposentadoria de algumas de suas principais jogadoras, cujo resultado, segundo Morten Soubak, é preocupante. Logo após a finalização dos Jogos Olímpicos, o técnico declarou:

Temos que pensar agora em novas meninas que talvez não tiveram chances ainda e também termos uma certa paciência. Eu vou buscar meninas de 16, 17, 20 anos e elas precisam de tempo para sentir o que é uma seleção adulta, como é o handebol desse nível. Temos que encontrar essas atletas de altíssimo nível, depois ensiná-las a filosofia que temos na seleção. Essas atletas existem (TERRA ESPORTE, 2016, p. s/n).

Afirmações como essas indicam que o handebol praticado por mulheres carece de uma estrutura mais consistente que possibilite às atletas e equipes o usufruto de condições capazes de garantir sua permanência no esporte, assim como sua própria subsistência. Considerando essas questões, este texto tem como objetivo analisar alguns aspectos relacionados à trajetória de mulheres que se dedicam à prática do handebol, destacando questões relacionadas à sua inserção e permanência na modalidade, assim como seu entendimento sobre o que é ser uma atleta profissional. Para tanto, focamos nosso olhar em uma equipe específica, a Associação dos Pais e Amigos do Handebol (APAHAND)/Universidade de Caxias do Sul UCS/Prefeitura de Caxias do Sul. Tal escolha justifica-se porque a equipe apresenta estrutura e condições que promoveram: a) a participação em campeonatos regionais, nacionais e internacionais; b) a manutenção de categorias de base; c) o investimento na manutenção de atletas (algumas vindas de outros estados); e d) a convocação de atletas de diferentes subcategorias para integrarem a seleção nacional.

Criada em 1997, a partir da fusão da S.E.R. ${ }^{1}$ Caí (São Sebastião do Caí - RS) com o Recreio Cruzeiro (Caxias do Sul - RS), esta equipe conta com o apoio da Universidade de Caxias do Sul (UCS). No momento de sua fundação, contava com 35 atletas e, desde então, já acolheu mais de 1600 jogadoras(es), distribuídas(os) entre projetos sociais, núcleos de treinamento e categorias de base. No ano de 2005, sua comissão técnica decidiu investir na equipe adulta de mulheres, buscando fortalecê-la mediante a contratação de atletas de outros estados. Tal decisão promoveu sua consolidação no handebol gaúcho.

O resultado desse investimento aflorou em 2009, quando a equipe conseguiu resultados suficientes para participar da Liga Nacional de Handebol, o campeonato de maior expressão no contexto nacional. Sua presença nessa competição aconteceu em todas as edições, até o ano de 2015. Nesse período, a equipe disputou a fase semifinal por duas vezes. Entretanto, em 2016, o grupo de atletas ausentou-se da competição em razão de questões financeiras, mas retornou em 2017. Sua trajetória acumula várias conquistas: heptacampeonato estadual, bicampeonato da Copa Sul de Handebol, tricampeonato Gaúcho Universitário, Campeonato da Copa Cruzamento de Handebol, vice-campeonato Brasileiro Universitário, duas vezes o vice-campeonato da Copa do Brasil, campeonato e vice-campeonato dos Jogos Abertos Brasileiros (JAB), tetracampeonato dos Jogos Intermunicipais do Rio Grande do Sul (JIRGS) e tetracampeonato da Copa Mercosul de Handebol.

Para a realização da pesquisa, foi adotado o aporte teórico-metodológico da História Oral, entendida como uma técnica de produção e tratamento de entrevistas, uma metodologia e uma 
fonte de pesquisa (ALBERTI, 2010). Operar com suas ferramentas revelou-se promissor uma vez que ainda são ínfimas as pesquisas de cunho sociocultural que focalizam o handebol e, mais especificamente, o handebol praticado por mulheres. Tomar a oralidade como uma ferramenta que narra as vivências esportivas das atletas e suas experiências pessoais, familiares, profissionais, comunitárias e sociais (MARTINELLI, 2003) implica produzir estratégias de visibilidade de histórias pouco registradas, assim como fontes para outras análises e investigações.

Desse modo, as narrativas produzidas não são tomadas como "a verdade" sobre 0 que foi dito, mas como uma versão produzida, a partir das representações de quem as narrou, sendo conformadas pela visão de mundo e experiências vividas (PESAVENTO, 2005).

Com o objetivo de analisar a trajetória das atletas da equipe adulta da APAHAND/UCS/ Prefeitura de Caxias do Sul, bem como o que consideram ser uma profissional do esporte, entrevistamos as quinze integrantes e os membros da comissão técnica. As entrevistas foram realizadas de acordo com os procedimentos teórico-metodológicos do Projeto Garimpando Memórias $^{2}$, que contemplam as etapas de elaboração do roteiro, realização de entrevista em gravador digital, transcrição, copidesque, conferência por parte da pessoa entrevistada, assinatura da carta de cessão dos direitos autorais e publicação do texto online ${ }^{3}$.

No processo analítico as entrevistas foram cotejadas com outras fontes de pesquisa, tais como reportagens publicadas em jornais, dados disponibilizados em sites institucionais (International Handball Federation, Confederação Brasileira de Handebol e Federação Gaúcha de Handebol), o Atlas do Esporte no Brasil, o Atlas do Esporte do Rio Grande do Sul, livros e artigos publicados em periódicos científicos.

Tendo em vista os pressupostos teórico-metodológicos que fundamentam a pesquisa e seu material empírico, identificamos dois tópicos sobre os quais focamos nossa discussão: a) a inserção e a trajetória das atletas no handebol, b) o entendimento das atletas sobre o que significa ser uma profissional do esporte.

\section{ENTRANDO EM QUADRA: DA INSERÇÃO À PERMANÊNCIA NO ESPORTE}

A carreira esportiva de um(a) atleta envolve várias etapas desde a iniciação até a aposentadoria, entre as quais se destacam: as equipes em que atuou; a formação técnica, realizada por meio de treinamentos e competições; a ascensão ao alto nível, ou não; e a suspensão sistemática ou abrupta do esporte (MARQUES, 2008).

Tratando da iniciação esportiva, ressaltamos que o primeiro contato com o handebol, destacado pelas jogadoras da APAHAND/UCS/Prefeitura de Caxias do Sul, se deu no contexto educacional, nas aulas de Educação Física e escolinhas esportivas, ofertadas no contraturno escolar. $\mathrm{Na}$ maior parte dos casos, a relação entre a prática do handebol e os espaços educativos estende-se, ainda, durante toda a trajetória das atletas, de modo a associarem 0 desenvolvimento de suas carreiras esportivas ao ensino fundamental e médio e, posteriormente, à inserção na universidade.

Essa relação figura em vários estudos que mencionam aspectos históricos do handebol no Brasil, cujos argumentos mencionam que o desenvolvimento da modalidade se deu de

2 Projeto desenvolvido pelo Centro de Memória do Esporte. Aprovado pelo Comitê de Ética da UFRGS, sob o número 2007710.

3 Todas as entrevistas realizadas para essa pesquisa estão disponibilizadas no Repositório Digital do Centro de Memória do Esporte através do site http://www.repositorioceme.ufrgs.br/. 
modo bastante satisfatório no contexto da Educação Física Escolar. Tal situação é justificada em função da atuação, em meados da década de 1960, do francês Augusto Listello, que ofertou, no Brasil, cursos de handebol para professores(as) com ênfase nos aspectos didáticos do ensino do handebol voltado para contexto escolar (SILVA; FERREIRA; PASKO, 2011; ARANTES, 2010).

Como consequência, o handebol teve sua presença ampliada em várias regiões do país, efetivando-se como uma prática esportiva recorrente na Educação Física Escolar (PASKO, 2005; NUNES; MATTEDI, 2014; CAMARGO, 2016). Tal perspectiva parece ter surtido efeito na inserção das atletas da APAHAND/UCS/Prefeitura de Caxias do Sul no handebol, visto que quase todas iniciaram a praticá-lo nas aulas de Educação Física. Algumas vivenciaram essa modalidade desde a infância, outras iniciaram a praticá-la na adolescência, sem ter passado pelas categorias iniciais, e outras, no caminho oposto, destacam-se ainda muito jovens e são convidadas a jogar em categorias acima de sua idade.

Sobre a iniciação no handebol, identificamos que a idade das entrevistadas apresenta uma variação entre nove e quinze anos. Essa não homogeneidade no primeiro contato com 0 esporte acaba refletindo a própria formação da equipe, cuja faixa etária engloba atletas entre 18 e 26 anos.

Ao longo do processo de iniciação das atletas na modalidade, algumas pessoas influenciaram suas escolhas, sobretudo, amigos(as), professores(as) e treinadores(as). A motivação de familiares também foi apontada por várias atletas como determinante para sua inserção no esporte. Em suas entrevistas, Kassiane Oliveira de Lemos (2014) e Laís Bordin (2014) explicitaram que começaram a praticar handebol em função de terem uma irmã atuando na modalidade. Contudo, Pietra Pasqualon sinaliza que seu início na modalidade aconteceu por influência da mãe:

A minha mãe era jogadora, ela sempre me incentivava, pedia. Na real, já tentei fazer todo tipo de esportes, mas nunca dava certo, nunca conseguia me satisfazer. Quando comecei no handebol me achei e continuei. Mas foi por influência da minha mãe (PASQUALON, 2014, p. 04).

Em decorrência daquilo que fazem, pensam e dizem, a família e os amigos acabam contribuindo para a estruturação de um ambiente favorável à iniciação esportiva, configurandose, muitas vezes, em um alicerce a partir do qual despontam e se desenvolvem talentos esportivos (COUTINHO, 2014).

O contato com o handebol na escola, como uma experiência inicial no esporte, esteve relacionado a um caráter lúdico e pedagógico. No entanto, algumas das atletas entrevistadas, ao se destacarem na modalidade, passaram a ter oportunidades de atuar em equipes de outras escolas ou clubes, algumas delas, inclusive, em cidades distantes daquelas em que tiveram seu primeiro contato com o handebol. Tamara Aragon, em sua entrevista, narra como foi essa experiência,

[...] eu morava em Betim, cidade de Minas Gerais, e na escola onde eu estudava aconteciam alguns jogos. A minha turma jogava basquete e futsal, mas para poder participar tínhamos que jogar handebol, e foi aí que comecei a jogar handebol. Participei dos JERBS e a professora que treinava o handebol convidou-me para treinar com escolinha. Fui eu e outra menina, no início enrolei para ir, mas acabei indo treinar e depois de uma semana de treino participei de um campeonato. Eu não sabia nem bater o lateral, não sabia nada. Mas acabei gostando e já faz 
quatro anos que jogo fora de Minas Gerais. Joguei em Pindamonhangaba, depois Itapevi, ambas em São Paulo. Ano passado joguei em Novo Hamburgo, aqui no Rio Grande do Sul, e esse ano eu vim para Caxias do Sul (ARAGON, 2014, p. 01).

Essas oportunidades, por sua vez, demandaram uma maior dedicação das atletas, envolvendo 0 aumento de turnos dedicados aos treinamentos, presença recorrente em campeonatos e cobranças por bons resultados. Acrescida a essas exigências relacionadas ao jogar, a dedicação aos estudos também se fez sentir, na medida em que muitas das atletas recebem incentivos de escolas e/ou universidades, conforme pode ser visto nos excertos abaixo:

Quando eu estava na minha cidade era normal, ia pela manhã para a escola, depois chegava em casa, arrumava a casa, fazia as coisas para a minha mãe e saía para treinar. 0 treino era sempre lá pelas quatro, cinco horas, sempre treino. Em 2013, quando estava jogando no Castro Alves foi a primeira vez que eu saí de casa, chorava todos os dias. E era assim, a gente estudava das sete ao meio-dia, depois a gente tinha que voltar a uma e meia para a escola, tinha aula a tarde toda. Como eu era atleta e o treino era na escola, às vezes, dependendo do horário do treino, a gente saía 15 minutos antes da aula, colocava a roupa de treino, entrava em quadra e ficava até as nove (LIMA, 2014, p. 05).

A gente não tem muito tempo, tanto que a gente vive cansada. Mas geralmente eu acordo, estudo, almoço, volto para casa, se tiver tempo durmo, se não tiver tema para fazer. A gente fica dois, três dias sem falar com a família porque tem que descansar, estudar ou coisa assim. A gente acostuma, a saudade tem que aguentar, não adianta. É difícil, mas ao longo do tempo vai acostumando e vai virando rotina (MATTOS, 2014, p. 05).

Essas narrativas evidenciam um marco na trajetória esportiva dessas atletas, em que o handebol é ressignificado, assumindo assim "características associadas ao sentido oficial do esporte, onde se prioriza o resultado da disputa e ocorre a cobrança de um alto rendimento obrigatório aos participantes" (LEONARDO FILHO, 2016, p. 43). Desse modo, o esporte deixa de ser uma diversão para assumir outra configuração, em que as atletas precisam assumir compromissos, em razão das oportunidades oriundas de suas performances. Nessa etapa, novamente, a família apresenta-se como um elemento importante, seja para estimular e apoiar as jogadoras, em função das mudanças e incremento de responsabilidades, seja para contribuir para a escolha por tornarem-se atletas para além do contexto da Educação Física vivenciado na escola.

Marques (2008, p. 38), ao analisar o futebol, destaca "que o papel dos pais no desenvolvimento da carreira de atletas é crucial e tem influência direta inclusive no nível de desempenho que podem alcançar". Essa constatação pode ser observada na narrativa de várias entrevistadas, quando mencionam a reação da família diante da escolha pela dedicação ao handebol.

No começo sempre tinha aquelas coisinhas assim: 'Ah, para que tu vais todos os dias treinar, se isso é só uma brincadeira' ou 'Você é nova'. Mas a partir do momento que eles perceberam que eu queria realmente isso como profissão, para a minha vida, eles encararam juntos e me ajudam muito. Por exemplo, se eu estou indo em algum jogo e aconteceu qualquer coisa familiar, eles tentam não me contar para não me abalar, encaram isso como um trabalho mesmo (MATTOS, 2014, p. 03). 
A minha mãe sabia que lá não ia ter futuro nenhum para mim, e eu tinha que arriscar de qualquer jeito a vir. Ela sabe que sou uma pessoa bem cabeça, sabe o que quero, que não iria fazer nenhuma besteira e que se eu visse que não ia dar para mim eu voltaria para casa. Depois que eu vim morar aqui, ligava sempre que dava e contava como estava sendo aqui, ela encarou numa boa. Até porque ela sabe que sempre fui batalhadora, sempre corri atrás dos meus objetivos (MATEUS, 2014, p. 08).

O modo como a família lida com o desenvolvimento e o crescimento das atletas tem relação com as experiências e expectativas que se criam diante de possíveis oportunidades. Em função disso, muitas das decisões referentes à carreira são influenciadas pelas pessoas envolvidas na história e na trajetória esportiva das atletas, tanto aconselhando e estimulando como, em vários momentos, apoiando as escolhas que elas fazem.

De acordo com Côté (1999), o papel dos pais vai modificando-se de acordo com as mudanças que ocorrem na carreira esportiva do(a) filho(a). No handebol, modalidade analisada neste artigo, há uma resistência inicial, por parte da família, com relação à prática deste esporte. Mas, com o passar do tempo, e com a percepção da dedicação da atleta, a prática esportiva passa a ter maior credibilidade, levando a família a apoiar a continuidade da carreira.

Meus pais entenderam, mas foi difícil, porque saí menor de idade. Para sair eles precisavam assinar uma permissão, nessa hora minha mãe não queria me deixar ir, então conversei, pedi e no final autorizaram (VIEIRA, 2014, p. 05).

Então, minha mãe não me apoia muito no handebol, ela acha que eu tenho que ficar lá com ela, mas a minha avó já dá todo o apoio, ela fala: 'Ah não! Se você gosta tem que ir mesmo'. Mas dá aquela tristeza, porque é muito longe de Minas daqui e a gente vai para casa só quando tem férias mesmo, uns dez, quinze dias e no final do ano, então eles não reagem muito bem eu jogar fora, mas apoiam, é o que eu gosto (ARAGON, 2014, p. 03).

Foi meio complicado, porque, a princípio, o meu pai não é atleta, então ele pensava que era só por lazer. Ele não concordou muito, mas a minha mãe sempre foi atleta, ela me incentivou. Aí quando eu vim para cá, e eles viram que os meus passos estavam aperfeiçoando e que eu estava começando a ser reconhecida, eles começaram a me apoiar. Porque eles viram que era isso que eu queria (COSTA, 2013, p. 03).

Ainda com relação ao impacto causado na família, no que tange à afirmação do desejo de atuar como atletas, emerge o receio acerca do afastamento do núcleo familiar, sobretudo, quando as esportistas precisam viver em outra cidade ou estado. Tal situação parece se amenizar quando, paralelamente ao handebol, existe a possibilidade de qualificar a formação profissional.

É o esporte que está me dando o estudo? 'É! Você tem que se dedicar ao esporte, mas o principal é o estudo'. No final do ano passado fiz vestibular, vou começar mais um curso. Isso só foi possível através do handebol, o handebol está me dando a faculdade, e fora isso tem o meu salário. [...] A gente fala assim, que no futebol as pessoas pensam mais no dinheiro, que são milhões. Não! No handebol no máximo é o seu estudo e um salariozinho (MATEUS, 2014, p. 03-04).

Ambas as atletas, em suas entrevistas, destacam a importância da relação que se estabelece entre a atuação no esporte e a possibilidade de estudar. Daniele Coelho, com 26 anos na época da entrevista, pontua que já estaria velha para projetar grandes conquistas em sua carreira como, por exemplo, servir à seleção brasileira. Winnie Cândido, com 20 anos, 
ressalta que o handebol é prioridade na sua vida e, nesse sentido, a chance de possuir bolsa de estudo the possibilita maior qualificação e conquistas para além da quadra.

Alguns estudos que focalizam aspectos relacionados ao abandono da carreira esportiva por atletas de diferentes modalidades (HALLAL et al., 2004; BARA FILHO; GARCIA, 2008; ROCHA et al., 2011) indicam que um dos motivos para essa desistência acontece em função dos limites que enfrentam para conciliar a carreira esportiva com a continuidade de seus estudos. No caso das atletas que compõem a pesquisa, apesar de vivenciarem algumas dificuldades para aliar seus estudos com a carreira esportiva, reconhecem que tanto a comissão técnica quanto a instituição de ensino à qual estão vinculadas contribuem para que possam manter um bom rendimento nos treinos e competições assim como na sua trajetória universitária. Essa estratégia não se dá isoladamente, visto que grande parte das equipes de handebol que disputam as competições nacionais tem forte ligação com instituições de ensino superior. No ano de 2014, por exemplo, das doze equipes que disputaram a Liga Nacional de Handebol Feminino, oito mantinham convênio com alguma universidade. Tal conjuntura é fundamental na carreira dessas mulheres, seja porque lhes garante uma formação universitária seja porque contempla algo que nas suas narrativas aparece como a caracterização de uma relação profissional com o esporte.

Ao serem indagadas sobre o que entendem por "profissional do handebol", boa parte das atletas mencionou a existência de algumas demandas e compromissos com a modalidade, tais como ter responsabilidade, treinar com afinco, cuidar da alimentação e buscar concentração para enfrentar os jogos e as competições, como é visto nos excertos que seguem:

Eu considero que ser profissional é abrir mão de coisas que qualquer pessoa que não faz esporte não abriria. Tipo, família, festa, porque tem gente que não deixa de fazer festa por causa de competição, e outras coisas assim, sabe, deixar de estar perto de pessoas que tu gosta. Ter uma alimentação saudável, não pode comer qualquer coisa, isso é ser atleta (LEMOS, 2014, p. 06, grifo nosso).

Quando tu queres levar isso para a tua vida, tu queres que seja o teu divertimento, mas também o teu compromisso, que não seja só um lazer, mas onde tu te dediques. É vir todo dia nos treinos, querer crescer, conhecer coisas novas, isso o handebol pode te proporcionar (MELLO, 2014, p. 02).

O que eu entendo por atleta profissional é aquele atleta que tem um vínculo com uma equipe. Por exemplo, eu estudo e tenho a minha vida, mas se tem um jogo e a equipe precisa de alguma coisa, tenho que cumprir com as responsabilidades que combinei com o clube, tenho que representá-lo! Acho que para mim o profissionalismo é isso (SILVA, 2014, p.02).

Abrir mão de determinadas práticas, que outras profissões não exigem, parece ser uma compreensão difundida entre algumas atletas da equipe, que, em grande medida, associam o ser profissional à dedicação ao esporte. No entanto, há atletas que compreendem essa relação a partir do vínculo que estabelecem com uma equipe e sua responsabilidade dentro desse coletivo.

Se considerarmos o que está explícito na Lei 9.615, conhecida como a Lei Pelé, que dispõe sobre questões afetas ao profissionalismo no esporte nacional, percebemos que essas mulheres não se enquadram nessa categoria. Se aproximam das condições de trabalho que Carravetta (2006) categorizou como pseudoprofissão ao analisar a carreira de jogadores de categorias de base do futebol masculino. Ou seja, atuam nas equipes que lhes oferecem ajuda de custo, alimentação, habitação, vale-transporte, assistência médica e odontológica. 
Nas entrevistas realizadas identificamos essa pseudoprofissão uma vez que o vínculo das atletas da APAHAND/UCS/Prefeitura de Caxias do Sul se dá com uma instituição de ensino que oferta alimentação, moradia, atendimento médico, academia, estudo e ajuda de custo.

Ser profissional do handebol, portanto, não está relacionado à profissionalização da modalidade, mas às relações que essas atletas desenvolvem com o handebol, ou com uma equipe que integram. Significa, em grande medida, ter oportunidade de alçar condições que Ihes permitam permanecer jogando e, ao mesmo tempo, realizar algo que lhes qualifique para o trabalho no futuro, isto é, para terem uma profissão! Mais do que uma carteira profissional assinada, ter a chance de estudar e de ter moradia, alimentação e atendimento médico figura como critério de profissionalização e de garantia de que o handebol não é apenas uma ocupação.

A trajetória dessas atletas, desde sua inserção no esporte até o momento que este se torna central em suas vidas, é marcada por demandas e oportunidades para viver do e para o handebol.

\section{ALGUMAS CONSIDERAÇÕES}

Construir uma carreira sólida dentro de qualquer esporte demanda investimento, dedicação, abdicação e, muitas vezes, persistência. A análise da trajetória das atletas da equipe adulta da APAHAND/UCS/Prefeitura de Caxias do Sul e do seu entendimento sobre o que é ser atleta profissional possibilitou compreender como essas atletas vão significando e ressignificando suas trajetórias esportivas, consoante às possibilidades de atuar no esporte.

Cabe destacar que o handebol, mesmo não tendo a visibilidade e o investimento necessário para que seja reconhecido como uma modalidade de expressão no contexto nacional, assume um espaço relevante na vida dessas mulheres, na medida em que possibilita a continuidade dos estudos para além da educação básica. Por meio do handebol, elas vislumbram a realização de um curso superior e, assim, garantir, no futuro, alguma profissão, relacionada ao esporte ou não.

A trajetória dessas atletas é marcada por dois momentos: o primeiro está atrelado à iniciação e permanência no esporte, em que percebem uma ressignificação na relação que estabelecem com o handebol. De uma prática lúdica e sem compromissos, regida somente pelo prazer de jogar, decorre o que mencionam ser "levar o esporte a sério". Essa nova dimensão afeta a vida das atletas dentro e fora do campo, em virtude das mudanças na relação com amigas(os) e familiares, em função da dedicação ao esporte. Emenda-se a isso a relação que elas estabelecem com o seu próprio corpo, visto que uma série de exigências passam a integrar o seu cotidiano, tais como treinos físicos, cuidado com a alimentação, tratamento de lesões, entre outras demandas necessárias para uma boa performance esportiva. 0 segundo momento refere-se à centralidade que o handebol ocupa em suas vidas, sobretudo, atinente à possibilidade de cursarem o ensino superior e construírem uma carreira (des)vinculada do esporte que praticam. Nessa perspectiva, algumas atletas escolhem estudar em instituições que mantenham equipes de handebol; outras, para continuar atuando no esporte, inscrevem-se em algum curso mantido pela instituição. De qualquer modo, todas entendem que o handebol Ihes possibilita garantir uma profissão vinculada, ou não, ao esporte, além de assegurarIhes, enquanto jogam, moradia, alimentação, assistência médica, ajuda de custo e estrutura adequada para os treinos. 
Se, por um lado, as narrativas dessas atletas apontam para uma situação específica e datada, por outro, entendemos que representam histórias e narrativas de muitas mulheres que vivem dessa e nessa modalidade, dadas as condições com as quais o handebol se estrutura em nosso contexto. Se cada caso é um caso, como explicita Fonseca (1999), "sua especificidade serve para oferecer uma alternativa, para abrir o leque de interpretações possíveis, não para fechar o assunto ou criar novas fórmulas dogmáticas" (p. 76).

Sendo assim, a partir da narrativa das atletas que integram a equipe adulta da APAHAND/UCS/Prefeitura de Caxias do Sul, apontamos que ser profissional do esporte equivale a dedicar-se e, sobretudo, ter condições mínimas de permanecer atuando nas quadras, vivendo do e para o handebol.

\section{REFERÊNCIAS}

ALBERTI, Verena. Manual de História Oral. Rio de Janeiro: FGV, 2010.

ARAGON, Tamara Christiny Serra. Depoimento de Tamara Christiny Serra Aragon: Projeto Garimpando Memórias. Porto Alegre: Centro de Memória do Esporte - Esef/UFRGS, 2014. Disponível em: <http://www.lume.ufrgs.br/handle/10183/126783>. Acesso em: 20 mar. 2017.

ARANTES, Gabriela Villela. A História do handebol em Minas Gerais. 2010. 55 f. Monografia (Graduação em Educação Física) - Universidade Federal de Minas Gerais. Minas Gerais. 2010.

BARA FILHO, Mauricio Gattás; GARCIA, Félix Garcia. Motivos do abandono no esporte competitivo: um estudo retrospectivo. Revista Brasileira de Educação Física e Esporte, v.22, n.4, p.293 - 300, 2008.

BORDIN, Lais. Depoimento de Lais Bordin: Projeto Garimpando Memórias. Porto Alegre: Centro de Memória do Esporte - Esef/UFRGS, 2014. Disponível em: <http://www.lume.ufrgs.br/ handle/10183/96153>. Acesso em: 20 mar. 2017.

CAMARGO, Philipe Rocha de. 0 desenvolvimento do handebol brasileiro a partir das políticas públicas do governo federal: da iniciação ao alto rendimento. 2016. $124 \mathrm{f}$. Dissertação (mestrado) - Programa de Pós-Graduação em Educação Física, Universidade Federal do Paraná, Curitiba, 2016.

CARRAVETTA, Elio Salvador Praia. Modernização da gestão no futebol brasileiro: perspectivas para a qualificação do rendimento competitivo. Porto Alegre: AGE, 2006.

COELHO, Lucas. Entre as melhores do mundo, Duda se decepciona com falta de investimento no handebol brasileiro. ESPNW online, 6 maio 2016. Disponível em: <http://espnw.espn.uol. com.br/entre-as-melhores-do-mundo-duda-se-decepciona-com-falta-deinvestimento-no-handebolbrasileiro/>. Acesso em: 20 mar. 2017.

COSTA, Lígia. Depoimento de Lígia Costa: Projeto Garimpando Memórias. Porto Alegre: Centro de Memória do Esporte - Esef/UFRGS, 2013. Disponível em: <http://www.lume.ufrgs.br/ handle/10183/90188>. Acesso em: 20 mar. 2017.

CÔTÉ, Jean. The influence of the family in the development of talent in sport. Sport Psychologist, v.13, p. 395-417, 1999. 
COUTINHO, Patrícia Alexandra dos Santos. 0 percurso para a excelência no desporto: Estudo retrospectivo de fatores de treino e psicossociais em voleibolistas portugueses. 2014. 224 f. Dissertação (Doutorado em Ciências do Desporto) - Centro de Investigação e Inovação em Desporto, Faculdade de Desporto da Universidade do Porto. Porto. 2014.

DANTAS, Marina de Mattos. Cartografias de um campo invisível: os anônimos jogadores do futebol brasileiro. 2017. 252 f. Tese (Doutorado em Ciências Sociais) - Programa de Estudos Pós-Graduados em Ciências Sociais, Pontifícia Universidade Católica de São Paulo, São Paulo, 2017.

FONSECA, Claudia. Quando cada caso NÃO é um caso: pesquisa etnográfica e educação. Revista Brasileira de Educação, n. 10, p. 58-78, jan./abr. 1999.

FRANCESCHINI, Gustavo. 'Handebol no país só piorou após título mundial', diz técnico da seleção. UOL Olimpíadas. 7 dez. 2015. Disponível em: <https://olimpiadas.uol.com.br/ noticias/2015/12/07/handebol-no-pais-so-piorou-apos-titulo-mundial-diz-tecnico-da-selecao.htm>. Acesso em: 20 mar. 2017.

HALLAL, Pedro Curi et al. Fatores intervenientes associados ao abandono do futsal em adolescentes. Revista Brasileira de Ciência e Movimento, v. 12, n.3, p. 27 - 32, 2004.

LEMOS Kassiane Oliveira de. Depoimento Kassiane Oliveira de Lemos: Projeto Garimpando Memórias. Porto Alegre: Centro de Memória do Esporte - Esef/UFRGS, 2014. Disponível em: $<$ http://www.lume.ufrgs.br/handle/10183/95494>. Acesso em: 20 mar. 2017.

LEONARDO FILHO, Luís Armando. A carreira de jogadores de voleibol de alto rendimento: Relatos sobre a própria formação esportiva. 2016. 116 f. Dissertação (Mestrado em Educação) - Faculdade de Filosofia Ciências e Letras de Ribeirão Preto da Universidade de São Paulo. Ribeirão Preto. 2016.

LIMA, Juliana Borges. Depoimento de Juliana Borges Lima: Projeto Garimpando Memórias. Porto Alegre: Centro de Memória do Esporte - Esef/UFRGS, 2014. Disponível em: <http://www. lume.ufrgs.br/handle/10183/104899>. Acesso em: 20 mar. 2017.

MARQUES, Mauricio Pimenta. Análise da transição da carreira esportiva de atletas de futebol da fase amadora para a fase profissional. 2008. 103f. Dissertação (Mestrado em Educação Física) - Faculdade de Educação Física. Universidade Federal de Minas Gerais. Minas Gerais, 2008.

MARTINELLI, Maria Lucia. Pesquisa Qualitativa: um instigante desafio. São Paulo: Veras, 2003.

MATEUS, Daniele Coelho. Depoimento de Daniele Coelho Mateus: Projeto Garimpando Memórias. Porto Alegre: Centro de Memória do Esporte - Esef/UFRGS, 2014. Disponível em: <http://www.lume.ufrgs.br/handle/10183/100152>. Acesso em: 20 mar. 2017.

MATTOS, Stefanni Rayane. Depoimento de Stefanni Rayane Mattos: Projeto Garimpando Memórias. Porto Alegre: Centro de Memória do Esporte - Esef/UFRGS, 2014. Disponível em: $<$ http://www.lume.ufrgs.br/handle/10183/97473>. Acesso em: 20 mar. 2017.

MELLO, Tais Regina. Depoimento de Tais Regina de Mello: Projeto Garimpando Memórias. Porto Alegre: Centro de Memória do Esporte - Esef/UFRGS, 2014. Disponível em: <http://www. lume.ufrgs.br/handle/10183/104914>. Acesso em: 20 mar. 2017. 
MIRANDA, Carlos Fabre. Como se vive do atletismo: um estudo sobre o profissionalismo e amadorismo no esporte, com olhar para as configurações esportivas. 2007. 140f. Dissertação (Mestrado em Ciências do Movimento Humano) - Escola Superior de Educação Física, Universidade Federal do Rio Grande do Sul, Porto Alegre, 2007.

NUNES, Camila da Cunha; MATTEDI, Marcos Antônio. Esporte e território: a territorialização do handebol no estado de Santa Catarina. Recorde: Revista de História do Esporte, v. 7, n. 2, p. 1-30, 2014.

PASKO, Vanessa Cerqueira. A popularidade do handebol no contexto escolar e extraescolar do Rio de Janeiro. 2005. 81f. (Mestrado em Ciências Sociais Aplicadas) - Universidade Gama Filho, Rio de Janeiro, 2005.

PASQUALON, Pietra Gauer. Depoimento de Pietra Gauer Pasqualon: Projeto Garimpando Memórias. Porto Alegre: Centro de Memória do Esporte - Esef/UFRGS, 2014. Disponível em: <http://www.lume.ufrgs.br/handle/10183/107953>. Acesso em: 20 mar. 2017.

PESAVENTO, Sandra Jatahy. História \& História Cultural. 2. ed. Belo Horizonte: Autentica, 2005.

ROCHA, Hugo Paula Almeida et al. Jovens Esportistas: profissionalização no futebol e formação na escola. Motriz, v.17, n.2, p. $252-263,2011$.

SARTORATO, Mayra; AZENHA, Manuela. Alexandra Nascimento: a melhor jogadora de handebol do mundo. Fox Sports Online, 08 mar. 2013. Disponível em: <http://www.foxsports. com.br/noticias/90895-alexandra-nascimento-a-primeira-brasileira-a-ser-eleita-a-melhor-jogadora-dehandebol-do-mundo>. Acesso em: 20 mar. 2017.

SILVA, Laís Bordin da. Depoimento de Laís Bordin da Silva: Projeto Garimpando Memórias. Porto Alegre: Centro de Memória do Esporte - Esef/UFRGS, 2014. Disponível em: <http://www. lume.ufrgs.br/handle/10183/96153>. Acesso em: 20 mar. 2017.

SILVA, Nadia Lima da et al. A Prática do Handebol na Cultura Físico-Esportiva de Escolares do Rio de Janeiro. Movimento, v. 17 n. 4, p. 123 - 143, 2011.

SOUZA JÚNIOR, Osmar Moreira de. Futebol como projeto profissional de mulheres: interpretações da busca pela legitimidade. 2013. 320 f. Tese (Doutorado em Educação Física) - Faculdade de Educação Física. Universidade Estadual de Campinas, Campinas, 2013.

TERRA ESPORTE. Morten Soubak garante que fica por mais 1 ano na seleção feminina de handebol. Terra, 16 ago. 2016. Disponível em: <https://esportes.terra.com.br/jogosolimpicos/2016/morten-soubak-garante-que-fica-por-mais-1-ano-na-selecao-feminina-de handebol,e3c3e8542d3d4dde1173340a3be9d83db301ftfp.html>. Acesso em: 20 mar. 2017.

VIEIRA, Samara da Silva. Depoimento de Samara da Silva Vieira: Projeto Garimpando Memórias. Porto Alegre: Centro de Memória do Esporte - Esef/UFRGS, 2014. Disponível em: <http://www.lume.ufrgs.br/handle/10183/104898>. Acesso em: 20 mar. 2017.

\section{Apoio financeiro:}

Coordenação de Aperfeiçoamento de Pessoal de Nível Superior (Capes). 